\title{
Responding to the needs of children with chronic health conditions in an era of health services reform
}

\author{
Anton R. Miller, Magdalena A. Recsky, Robert W. Armstrong
}

$\mathrm{B}$ etween $15 \%$ and $20 \%$ of children and adolescents live with a chronic physical, developmental, behavioural or emotional condition. ${ }^{1}$ Although diverse in terms of clinical characteristics, causes and treatments, chronic health conditions have a lot in common with regard to their impact on affected children and families and the specialized needs that they present to the health care system. ${ }^{2}$ Children with chronic health conditions are mostly referred to as "children with special health care needs." " A sizeable body of expert recommendations and increasing research evidence now exists in support of measures to reduce the adverse impact of these chronic conditions on children's health and development and on their families. However, adoption of these strategies into Canadian health services has been minimal. Although there are examples of innovation (e.g., the adoption of the Chronic Care Model to promote better care of people with chronic conditions by British Columbia's Ministry of Health Services and the implementation of the Ontario Family Health Network by Ontario's Ministry of Health and Long-Term Care), these models of care do not focus on the needs of children. We argue that the present era of health care restructuring, with its emphasis on primary care reform, preventive care and improving chronic disease management, represents an opportune moment for change.

Chronic health conditions affecting children and youth present unique features, with implications for management that differ from adults. First, the presence of a chronic health condition during the developmental period affects more than a child's medical status. Affected children are at much higher risk of disruptions to social and emotional development (including family and peer relationships), behaviour and educational achievement (including readiness to learn), with effects that may last a lifetime. ${ }^{4}$ Timely and appropriate intervention and support during the developmental period hold the prospect of benefits that extend to adult life $e^{5}$ through prevention of morbidity and psychosocial disability. Second, the presence of a chronic disease or disorder in a child has significant implications for the whole family, who have to cope with its immediate manifestations and the additional caregiving burden. ${ }^{4}$ Recent research highlights specific benefits to be derived from adopting a "child-in-family" approach when working with children with chronic health conditions and disabilities. ${ }^{6}$ Finally, the epidemiology of children's chronic health conditions differs from that of adults. The main chronic conditions of adults consist of a limited number of illnesses (e.g., hypertension, chronic obstructive pulmonary disease, arthritis and depression), all of which are encountered quite frequently in primary care settings and require medical treatments as a major modality of management. Children, on the other hand, are affected by a relatively large number of uncommon conditions ranging from birth defects and developmental disabilities to diabetes and cancer, with which the primary care physician may lack familiarity and confidence. In part for this reason, and in part because management and habilitation are aimed at medical stability as well as psychosocial development, the primary care physician is frequently required to spend considerable time coordinating efforts with multiple agencies and care providers, including hospitals, schools, public health agencies and social services.

How, then, does the present era of review, reform and redesign of health systems across Canada provide the opportunity to address the unmet health care needs of children and adolescents with chronic conditions? An emerging consensus identifies several principles as foundations of appropriate care: care that is comprehensive, coordinated and competent; ${ }^{7}$ care that supports integrated collaboration, management of clinical complexities, and child and family empowerment through written reports and dedicated discussion visits; ${ }^{8}$ and care that is child-specific and emphasizes coordination between tiers of the health care delivery system and between the health and education systems. ${ }^{5,9}$ Overall, these sources recognize the need to incorporate the developmental aspect of child health, implement better support systems for families and develop ways of monitoring the quality of long-term chronic care. These principles mesh well with the core recommendations that have emerged from federal reviews and provincial initiatives of the past decade and which call for a more integrated primary health care system, ${ }^{10,11}$ with better coordination between an increasing variety of primary care providers and a renewed emphasis on disease prevention and health promotion. ${ }^{10-14}$

In order to capitalize on this moment of opportunity, specific action is required on a number of fronts. First, through work with media and advocacy groups, we must raise public awareness about health reform recommendations in Canada being directly relevant to the improvement of health care services for children with chronic health conditions. Second, we need to ensure that the needs of children are not submerged within current and prospective reform efforts. Although federal and provincial documents may refer to conditions that affect both adults and children (e.g., diabetes care in British Columbia's 
provincial vision for chronic disease management), the situation and needs of children with the condition receive little attention (Dr. Jean-Pierre Chanoine, Clinical Professor, University of British Columbia and Head of Endocrinology and Diabetes Unit, Children's and Women's Health Centre of BC, personal communication, 2003). This makes neither economic nor moral sense. Economically, although few children compared with adults are affected by diabetes, the impact of this and other chronic conditions on the person and on society over a lifespan is large. Morally, the failure to fully acknowledge specific health needs that have been identified in the child population, and to translate these needs into action, is out of keeping with currently proposed principles for health care policies involving children. ${ }^{15}$ Third, systematic efforts are needed to ensure that current thinking and evidence regarding the needs of children with chronic health conditions and their families are incorporated into policies and practices for their care. The creation, implementation and testing of a child-focused chronic care model is one possible way of accomplishing this. The BC Chronic Care Model ${ }^{16}$ despite recent revisions, still does not acknowledge the social, developmental and emotional needs of individual children, the need for family-centred care or the interdisciplinary team work required.

What we need are new models of care that are capable of addressing these gaps through better organization of primary care and integration with other levels of care. We need to properly evaluate these models in a variety of settings (e.g., urban, rural, Aboriginal) to ensure that they successfully address the current gaps. Such initiatives would affirm the importance of a health system responsive to the needs of children and their families and would provide significant benefit to these children over the course of their lives.

From the Department of Pediatrics, University of British Columbia (Miller, Recsky, Armstrong) and the Centre for Community Child Health Research, British Columbia Research Institute for Children's and Women's Health (Miller, Armstrong), Vancouver, BC.

\section{Competing interests: None declared.}

Contributors: All 3 authors contributed substantially to the conception and design of the article. They drafted, edited and revised the article critically for important intellectual content, and all gave final approval of the version submitted for publication.

\section{References}

1. Newacheck PW, Strickland B, Shonkoff JP, Perrin JM, McPherson M, McManus M, et al. An epidemiologic profile of children with special health care needs. Pediatrics 1998;102(1 Pt 1):117-23.

2. Perrin JM. Health services research for children with disabilities. Milbank $Q$ 2002;80(2):303-24.

3. McPherson M, Arango P, Fox H, Lauver C, McManus M, Newacheck PW, et al. A new definition of children with special health care needs. Pediatrics 1998;102(1 Pt 1):137-40.

4. American Academy of Pediatrics. Psychosocial risks of chronic health conditions in childhood and adolescence. Pediatrics 1993;92(6):876-8.

5. Stein RE. Challenges in long-term health care for children. Ambul Pediatr 2001;1(5):280-8.

6. CanChild Centre for Childhood Disability Research. Children with disabilities in Ontario: a profile of children's services. Part 3: Factors affecting family-centred service delivery for children with disabilities. Hamilton: McMaster
University; 2003. Available: canchild.interlynx.net/reports/FCSPart3summaryforweb.pdf (accessed 2004 Oct 24).

7. American Academy of Pediatrics. General principles in the care of children and adolescents with genetic disorders and other chronic health conditions. Pediatrics 1997;99(4):643-4.

8. McDowell M, Klepper K. A 'chronic disorder' health-care model for children with complex developmental disorders. 7 Paediatr Child Health 2000;36(6):563-8.

9. Forrest CB. Outcomes research on children, adolescents, and their families: directions for future inquiry. Med Care 2004;42(4 Suppl):III19-23.

10. Kirby MJL, LeBreton M. The health of Canadians. The Federal Role: recommendations for reform. Ottawa: The Standing Senate Committee on Social Affairs, Science and Technology; 2002.

11. Romanow RJ. Building on values: the future of health care in Canada. Saskatoon: Commission on the Future of Health Care in Canada; 2002. Available: www.healthcarecommission.ca (accessed 2004 Oct 20).

12. Clair M. Emerging solutions: report and recommendations. Quebec: Commission d'étude sur les services de santé et les services sociaux.; 2000.

13. Fyke KJ. Caring for medicare: sustaining a quality system. Regina: Policy and Planning Branch Saskatchewan Health; 2001.

14. Mazankowski D. A Framework for Reform. Edmonton: Premier's Advisory Council on Health; 2001.

15. Aynsley-Green A, Barker M, Burr S, Macfarlane A, Morgan J, Sibert J, et al. Who is speaking for children and adolescents and for their health at the policy level? BM7 2000;321(7255):229-32.

16. Government of British Columbia. Ministry of Health Services. Chronic Disease Management. Victoria: The Ministry; 2003.

Correspondence to: Dr. Anton R. Miller, The Centre for Community Child Health Research, Children's and Women's Health Centre of BC, Room L 408, 4480 Oak St., Vancouver BC V6H3V4; fax 604 875-3569; amiller@cw.bc.ca

\begin{tabular}{|c|c|}
\hline 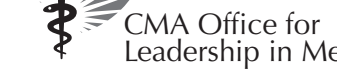 & $\begin{array}{l}\text { Bureau pour le leadership } \\
\text { en médecine de l'AMC }\end{array}$ \\
\hline \multirow[t]{3}{*}{$\begin{array}{l}\text { CMA Leadership Workshop for } \\
\text { W E I C A L } \\
2004 \\
\end{array}$} & $\begin{array}{l}\text { Come join in the } 10^{\text {th }} \text { anniversary } \\
\text { celebration of the CMA Leadership } \\
\text { Workshop for Medical Women, a } \\
\text { professional development event } \\
\text { dedicated exclusively to women } \\
\text { physicians with an interest in } \\
\text { leadership. In both plenary and small } \\
\text { group interactive sessions, learn from } \\
\text { leaders in the fields of medicine, law } \\
\text { and business. }\end{array}$ \\
\hline & $\begin{array}{l}\text { Featuring special keynote speaker } \\
\text { The Right Honourable Beverley } \\
\text { McLachlin, Chief J ustice of Canada }\end{array}$ \\
\hline & $\begin{array}{l}\text { Great networking opportunities, } \\
\text { prizes, gifts and more! }\end{array}$ \\
\hline & $\begin{array}{l}\text { Registration in this highly successful } \\
\text { workshop is limited so register early. }\end{array}$ \\
\hline Toronto, Ontario & $\begin{array}{l}\text { For information, or to be placed on } \\
\text { the preferred mailing list, contact: }\end{array}$ \\
\hline $\begin{array}{c}\text { ASSOCIATION } \\
\text { MEDDCAL } \\
\text { CANADIENNE }\end{array} \$ \begin{array}{l}\text { MANADIAN } \\
\text { ASSOCALATION }\end{array}$ & \multirow{2}{*}{$\begin{array}{l}\text { CMA Office for Leadership in Medicine } \\
800663-7336 \text { or } 613731-8610 \text { x2261 } \\
\text { Professional_Development@cma.ca }\end{array}$} \\
\hline chel.cel & \\
\hline
\end{tabular}

